\title{
THREE YEARS OF THE GLOBAL PRECIPITATION MEASUREMENT (GPM) MISSION
}

\author{
Gail Skofronick-Jackson, George Huffman, Walter Petersen
}

\author{
NASA Goddard Space Flight Center, Greenbelt, MD 20771 USA, 301-614-5720 \\ Gail.S.Jackson@nasa.gov, NASA Goddard, 301-614-6308, george.j.huffman@nasa.gov, NASA \\ Marshall Space Flight Center, 256-961-7408, walt.petersen@nasa.gov
}

\begin{abstract}
Water is essential to our planet Earth. Knowing when, where and how precipitation falls is crucial for understanding the linkages between the Earth's water and energy cycles and is extraordinarily important for sustaining life on our planet during climate change. The Global Precipitation Measurement (GPM) Core Observatory spacecraft launched February 27, 2014, is the anchor to the GPM international satellite mission to unify and advance precipitation measurements from a constellation of research and operational sensors to provide "next-generation" precipitation products. GPM is currently a partnership between NASA and the Japan Aerospace Exploration Agency (JAXA). Status and successes in terms of spacecraft, instruments, retrieval products, validation, and impacts for science and society will be presented.
\end{abstract}

Index Terms - Precipitation, microwave, satellite

\section{INTRODUCTION}

Precipitation is a key source of freshwater; therefore observing global patterns of precipitation and its intensity is important for science, society, and understanding our planet in a changing climate. In 2014, NASA and the Japan Aerospace Exploration Agency (JAXA) launched the Global Precipitation Measurement (GPM) Core Observatory (GPM-CO) spacecraft. The GPM-CO carries the most advanced precipitation sensors currently in space including a dual-frequency precipitation radar (DPR) provided by JAXA measuring the three-dimensional structures of precipitation and a well-calibrated, multi-frequency passive microwave imaging radiometer (GPM Microwave Imager GMI) providing wide-swath precipitation data. The GPM$\mathrm{CO}$ was designed to measure rain rates from $0.2-110.0 \mathrm{~mm}$ $\mathrm{h}^{-1}$ and to detect moderate to intense snow events. The GPM-CO serves as a reference for unifying the data from a constellation of about 10 (in 2016) partner satellites to provide next-generation, merged precipitation estimates globally and with high temporal ( 0.5 to 3.0 hours) and spatial (5 to $15 \mathrm{~km}$ ) resolutions [1], [2] (and see Figure 1).

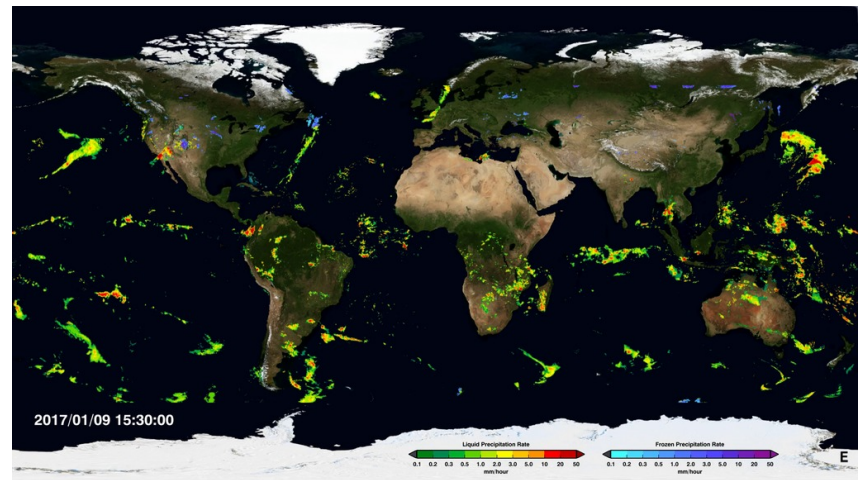

Figure 1: The multi-satellite merged product called IMERG on $01 / 09 / 2017$ at $1530 \mathrm{UTC}$.

The GPM-CO is a key part of the GPM Mission, which is defined to encompass the multi-satellite unified precipitation estimates. Through improved measurements of rain and snow, precipitation data from GPM provides new information such as: details on precipitation structure and intensity; observations of hurricanes and typhoons as they transition from the tropics to mid-latitudes; data to advance near-real-time hazard assessment for floods, landslides and droughts; inputs to improve weather and climate models; and insights into agricultural productivity, famine, and public health. Since launch, GPM teams have calibrated instruments, refined precipitation retrieval algorithms, expanded science investigations, and processed and disseminated precipitation data for a range of applications.

The Global Precipitation Measurement (GPM) Core Observatory (GPM-CO) spacecraft is an advanced successor to TRMM, with additional channels on both the Dualfrequency Precipitation Radar (DPR) and on the GPM Microwave Imager (GMI) with capabilities to sense light rain and falling snow [2]. The GPM-CO, also a NASAJAXA partnership, was launched in 18:37 UTC 27 February 2014 and currently operates in a non-sun-synchronous orbit with an inclination angle of $65^{\circ}$. The inclined orbit allows the GPM-CO to sample precipitation across all hours of the day from the tropics to the Arctic and Antarctic circles and for observing hurricanes and typhoons as they transition from the tropics to mid-latitudes. GPM expands TRMM's reach not only in terms of global coverage, but also through sophisticated satellite instrumentation, the inter-calibration of datasets from other microwave radiometers, coordinated 
merged precipitation data sets, reduced latency for delivering data products, simplified data access, expanded global ground validation efforts, and integrated user applications. Because of the application focus of GPM, the public release of precipitation products is required in nearreal-time (1-5 hours after the observations are obtained).

The Global Precipitation Measurement (GPM) mission has several scientific objectives including (1) advancing precipitation measurements from space, (2) improving knowledge of precipitation systems, water cycle variability and freshwater availability, (3) improving climate modeling and prediction, (4) improving weather forecasting and 4D reanalysis, and (5) improving hydrological modeling and prediction [2]-[3].

\section{INSTRUMENT STATUS AND SUCCESSES}

The GMI and DPR together provide a powerful synergistic tool to assess precipitation micro- and macrostructure, intensity and phase globally at relatively high resolutions. The DPR with $\mathrm{Ku}$-band $(35.5 \mathrm{GHz})$ and $\mathrm{Ka}-$ band $(13.6 \mathrm{GHz}$ ) channels provides three-dimensional (3D) precipitation (rain and snow) particle structure with vertical resolution of $250 \mathrm{~m}$, a horizontal resolution of $\sim 5 \mathrm{~km}$, and swath width of $125 \mathrm{~km}(\mathrm{Ka})$ and $245 \mathrm{~km}(\mathrm{Ku})$ (Hou et al. 2014). The DPR was extensively calibrated pre-launch [4] and meets mission requirements (e.g., [5], [6]).

The GMI is a 13-channel conically scanning microwave radiometer. GMI provides wide-swath $(885 \mathrm{~km}) \mathrm{TB}$ data to estimate surface precipitation at resolutions ranging from 5$25 \mathrm{~km}$ depending on frequency. Design requirements for GMI were driven both by requirements to build a priori databases to support Bayesian microwave precipitation retrieval algorithms (e.g., [7]) as well as to provide a reference radiance calibration standard for the GPM constellation [1], [2]. The design features needed to meet the requirements include a shroud over the warm load to eliminate solar intrusions, a robust reflective antenna coating to minimize emissivity issues, and the addition of noise diodes for a four point calibration of the window channels [8], [9]. The GMI instrument meets its performance requirements [9] and has been deemed one of the best calibrated conically scanning passive microwave radiometers in space with brightness temperature accuracy for all channels within $0.4 \mathrm{~K}$ and stability within $0.2 \mathrm{~K}$ [10].

The prime mission lifetime (instrument design life) is 3 years (to May 2017) but fuel is projected to last well beyond that, with the GPM Core Observatory lasting potentially 20+ years if the instruments do not fail.

\section{RETRIEVAL STATUS AND SUCCESSES}

Relative to current global rainfall products, GPM data products are characterized by: (1) more accurate instantaneous precipitation measurements (especially for light rain and cold-season solid precipitation), (2) more frequent sampling by an expanded constellation of domestic and international microwave radiometers including operational humidity sounders, (3) inter-calibrated microwave brightness temperatures from constellation radiometers within a unified framework, and (4) physicalbased precipitation retrievals from constellation radiometers using a common a priori cloud/hydrometeor database derived from GPM Core sensor measurements.

One clear success with retrieval products include proof that GPM is able to detect and estimate falling snow (Fig. 3). A global evaluation technique compares zonal means among the various GPM instrument algorithms and established precipitation estimates such as the Global Precipitation Climatology Project (GPCP) data sets [15] and, over ocean, the Merged CloudSat, TRMM, Aqua version 2 (MCTA2) data [16]. Both GPCP and MCTA2 include a variety of input data sets selected for utility in precipitation estimation at both low and high latitudes. Figure 4 shows the global zonal means for 2015 for land and ocean, ocean only, and land only. The GPM zonal accumulations underestimate with respect to the MCTA at higher latitudes. This is most attributable to the fact that the DPR minimum detectable reflectivities correspond to minimum rain rates of approximately $0.2 \mathrm{~mm} \mathrm{~h}^{-1}$. Since much of the higher latitude precipitation is light, and CORRA and GPROF are based on DPR estimates, GPM is low in the higher latitudes. Land surfaces tend to complicate the retrieval process and the various algorithms use different approaches to mitigate surface (emissivity and clutter) issues. A high latitude, light precipitation solution for GPROF is being implemented in the upcoming algorithm Version 05 release in 2017.
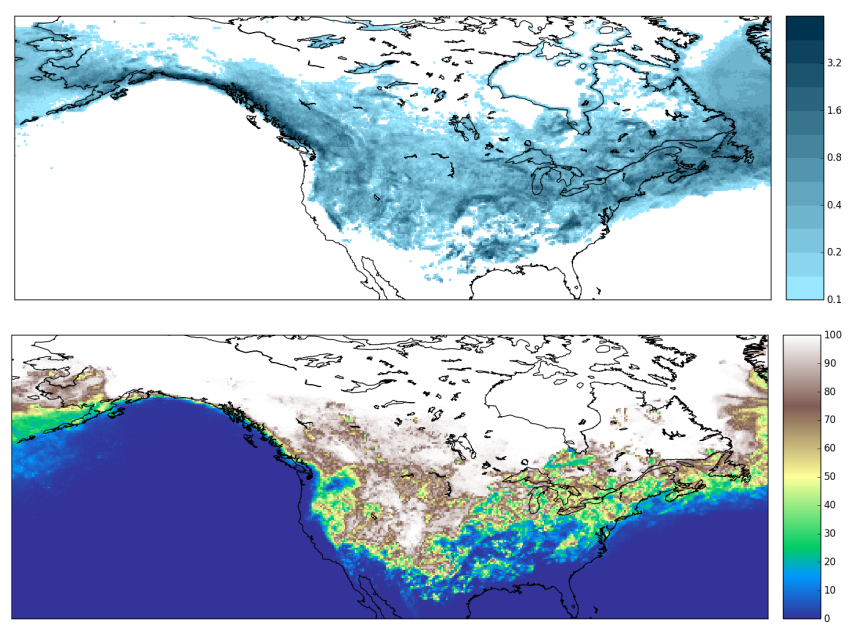

Figure 2: The (top plot) average and (bottom) fraction of precipitation that was identified as falling snow (and not liquid rain) from December 2014 - February 2015 from the GMI GPROF

(Version 04) retrieval algorithm. The average includes zeros. 


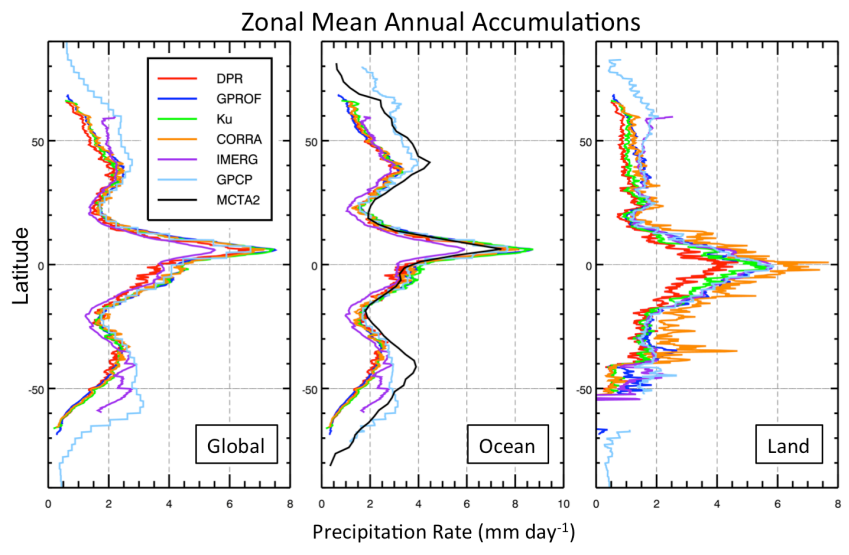

Figure 3: Zonal precipitation averages (in $\mathrm{mm} \mathrm{day}^{-1}$ ) for the full annual cycle in 2015. The five estimates are: GPM DPR (dualfrequency radar in red), GPM GPROF (GMI passive radiometer in blue), GPM Ku (single-frequency radar in green), GPM CORRA (DPR+GMI in orange), IMERG (GPM merged with constellation estimates in purple), GPCP global estimates (in light blue), and MCTA2 estimates over ocean (in black, covering the years 20072010). The GPCP is Version 2.3, MCTA is Version 2, IMERG is

Version 03, and the other GPM products are Version 04.

The Precipitation Processing System (PPS) processes, analyzes, distributes, and archives data from GPM, partner satellites and TRMM [11]. PPS is responsible for converting scientist provided algorithms into suitable code for producing the precipitation products and meeting data latency requirements. In the spring of 2017, PPS will start releasing the $5^{\text {th }}$ version of reprocessed precipitation estimates from improved algorithms. These improved algorithms will improve the light rain, falling snow, merged products as well as the $3 \mathrm{D}$ precipitation particle size distributions available from the DPR instrument. PPS also works closely with the Japanese data processing center.

\section{VALIDATION EFFORTS}

GPM validation activities [12] consider not only direct validation of the satellite products, but also validation of the relationships between physical and radiatively observed properties as well as via integrated applications that embrace cloud resolving models and coupled land surface/cloud resolving models used in hydrologic applications.

Several field campaigns have occurred for focused physical validation and integrated validation (Fig 4). Meanwhile, direct validation efforts compare GPM satellite data to similar measurements from the national network of operational weather radars [13]. The goal of this Validation Network (VN) is to identify and resolve significant discrepancies between the US national network of ground radar observations and satellite observations. In addition, NOAA's Multiple Radar Multiple Sensor (MRMS) system [14] combines data streams from multiple radars, satellites, surface observations, upper air observations, lightning map

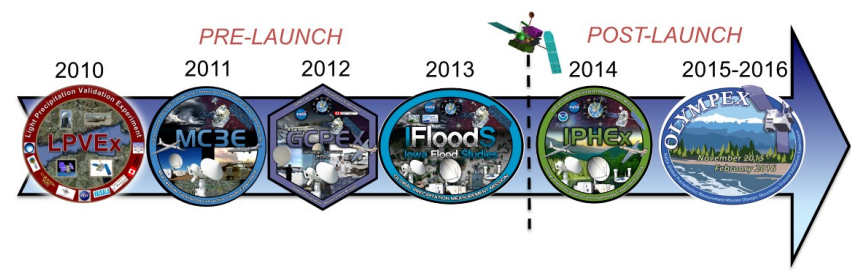

Figure 4: GPM field campaign dates and logos.

reports, rain gauges and numerical weather prediction models to produce a suite of products every two minutes at a resolution of $1 \mathrm{~km}$ and with 31 vertical levels.

Re-evaluation of the reprocessed (new, Version 5) GPM algorithms is underway in 2017. In addition, validation has shown that GPM meets its Level 1 Mission requirements. Basically, these requirements are that the instantaneous rain rate estimate has a bias and random error of $<25 \%$ at rain rates of $10 \mathrm{~mm} / \mathrm{hr}$ and $<50 \%$ at rain rates of $1 \mathrm{~mm} / \mathrm{hr}$ over a $0.5^{\circ}(50 \times 50 \mathrm{~km})$ grid scale.

\section{SOCIETAL APPLICATIONS}

The precipitation data provided by GPM is vital to understanding how weather and climate impact both our environment and Earth's water and energy cycles. Through improved measurements of rain and snow, precipitation data from TRMM and GPM can reveal new information on hurricane eyewalls and intensity, measure hazard-triggering rainfall events, provide inputs into climate and land surface models, and offer new insights into agricultural productivity and world health [3]. GPM's remotely sensed precipitation data enable a diverse range of applications across agencies, research institutions and the global community, including: Tropical Cyclones, Extreme Weather, Floods, Landslides, Land Surface Models, Climate Prediction, Soil Moisture, Agriculture, Freshwater Availability, and World Health. GPM's data is used in, for example, on-line databases of flood, landslide, and fire susceptibility maps.

\section{PARTNERS AND SCIENCE TEAMS}

The strongest partnership of GPM is between NASA and the Japanese Aerospace and Exploration Agency (JAXA) that built DPR and launched the GPM Core Observatory. Because of the international nature of GPM, country, agency, and university partnerships are formed independently with both NASA and JAXA for sharing spacecraft data, ground validation measurements and scientific expertise. For NASA, these international partnerships are at no cost to the US Government and are formalized through the selection of an unsolicited proposal submitted to NASA Headquarters. As Jan 2017, there are currently 25 formalized international partners with NASA. In addition, both NASA and JAXA have Science Teams with funded Principal Investigators and their teams. The 
NASA science team currently consists of 60 United States Principal Investigators investigating TRMM and GPM Science, algorithms, validation, climate and applications.

\section{CONCLUSIONS}

The GPM mission is well on its way to providing essential data on precipitation (rain and snow) from micro to local to global scales via providing precipitation particle size distributions internal to the cloud, $5-15 \mathrm{~km}$ estimates of regional precipitation and merged global precipitation. Once TRMM data is recalibrated to the high quality standards of GPM (and as GPM continues to operate), TRMM and GPM together, with partner data) can provide a $25-30+$ year record of global precipitation. Scientists and hazard decision makers all over the world value GPM's data.

In quantifying precipitation, a key Earth system component, the GPM mission provides fundamental knowledge of the water cycle and compliments other NASA satellite missions such as the Gravity Recovery and Climate Experiment (GRACE), that measures changes in groundwater levels in underground aquifers (among other observations); the Soil Moisture Active Passive (SMAP) satellite; Aquarius (while it was operating), that observed ocean salinity; and CloudSat, which measures the properties of clouds and light precipitation. Integrated multidisciplinary scientific investigations can provide greater understanding of our complex Earth system. GPM has and will continue to provide valuable and freely accessible precipitation data for science and society.

The presentation associated with this paper will address the significant and important findings used in the (1) GPM Senior Review Proposal and Panel Review for continuing funding for operations for the next 2 years (FY18-FY19), and (2) End-of-Prime Review where proof of accomplishing all mission requirements are presented.

\section{REFERENCES}

[1] Arthur Y. Hou, Ramesh K. Kakar, Steven Neeck, Ardeshir A. Azarbarzin, Christian D. Kummerow, Masahiro Kojima, Riko Oki, Kenji Nakamura, Toshio Iguchi, The Global Precipitation Measurement (GPM) Mission, Bulletin of the American Meteorological Society, May 2014.

[2] Gail Skofronick-Jackson, and co-authors: Global Precipitation Measurement for Science and Society, in press BAMS, 2017 (DOI: http://dx.doi.org/10.1175/BAMS-D-15-00306.1).

[3] Dalia Kirschbaum, and co-authors, "NASA's Remotely-sensed Precipitation: A Reservoir for Applications Users", BAMS, 2017 (DOI: http://dx.doi.org/10.1175/BAMS-D-15-00296.1).

[4] Kojima, M., and Coauthors, 2012: Dual-frequency precipitation radar (DPR) development on the global precipitation measurement (GPM) core observatory. Earth Observing Missions and Sensors:
Development, Implementation, and Characterization II, H. Shimoda et al., SPIE Proc., 85281A, doi 10.1117/12.976823.

[5] Kubota, T., T. Iguchi, M. Kojima, L. Liao, T. Masaki, H. Hanado, R. Meneghini, and R. Oki, 2016: A statistical method for reducing sidelobe clutter for the $\mathrm{Ku}$-band precipitation radar onboard the GPM Core Observatory. J. Atmos. Oceanic Technol., 33 (7), 1413-1428.

[6] Toyoshima, K., H. Masunaga, and F.A. Furuzawa, 2015: Early Evaluation of $\mathrm{Ku}$-and Ka-Band Sensitivities for the Global Precipitation Measurement (GPM) Dual-Frequency Precipitation Radar (DPR). SOLA, 11, 14-17, doi:10.2151/sola.2015-004.

[7] Kummerow, C. D., D. L. Randel, M. Kulie, N.-Yu Wang, R. Ferraro, S. J. Munchak, and V. Petkovic, 2015: The Evolution of the Goddard PROFiling Algorithm to a Fully Parametric Scheme. J. Atmos. Oceanic Technol., 32, 2265-2280.

[8] Draper, D. W., D. A. Newell, F. J. Wentz, S. Krimchansky, and G. Skofronick-Jackson, 2015a: The Global Precipitation Measurement (GPM) Microwave Imager (GMI): Instrument Overview and Early On-orbit Performance. IEEE J. Sel. Topics Geosci. Remote Sens., doi:10.1109/JSTARS.2015.2403303.

[9] Draper, D. W., D. A. Newell, D. McKague and J. Piepmeier, 2015b: Assessing Calibration Stability using the Global Precipitation Measurement (GPM) Microwave Imager (GMI) Noise Diodes. IEEE J. Sel. Topics Geosci. Remote Sens., 8, doi:10.1109/JSTARS.2015.2406661.

[10] Wentz, F. J. and D. Draper, 2016: On-Orbit Absolute Calibration of the Global Precipitation Measurement Microwave Imager. J. Atmos. Oceanic Technol., 33, in early release. doi:10.1175/JTECH-D-15-0212.1.

[11] Precipitation Processing System: pps.gsfc.nasa.gov, Jan 2017.

[12] GPM Validation: http://pmm.nasa.gov/science/groundvalidation, accessed 9 Jan 2017.

[13] Kirstetter, P. E., Y. Hong, J. J. Gourley, Q. Cao, M. Schwaller, and W. Petersen, 2014: A research framework to bridge from the GPM mission core satellite to the constellation sensors using ground radar-based National Mosaic QPE. In L. Venkataraman, Remote Sensing of the Terrestrial Water Cycle. AGU books Geophysical Monograph Series, Chapman monograph on remote sensing. John Wiley \& Sons Inc. ISBN: 1118872037.

[14] NOAA Multi-Radar/Multi-Sensor dataset for validation: http://www.nssl.noaa.gov/projects/mrms/ accessed 9 January 2017.

[15] Adler, R. F., and Coauthors, 2003: The version-2 global precipitation climatology project (GPCP) monthly precipitation analysis (1979-present). J. Hydrometeor., 4, 1147-1167.

[16] Behrangi, A., G. Stephens, R. F. Adler, G. J. Huffman, B Lambrigtsen, and M. Lebsock, 2014: An Update on the Oceanic Precipitation Rate and Its Zonal Distribution in Light of Advanced Observations from Space. J. Climate, 27, 3957-3965. doi: http://dx.doi.org/10.1175/JCLI-D-13-00679.1 